of this ulcer, with some increased vascularity of the mucous surface, and sundry small ulcers and erosions. The pyloric segment, which, as before observed, formed a separate compartment, included the right half nearly of the great curvature, and was the healthiest portion of the organ, being quite free from ulceration. The pylorus was normal. The total capacity of the stomach was greatly augmented ; it was generally in a state of chronic catarrb, and it contained some of the melænic matter which was vomited during the last days of life, but no coagula. The duodenum was considerably dilated and contorted, the adhesion of the stomach to it just at its termination having apparently produced some constriction of the gut there; it also contained melænic matter. The liver had some slight adhesions of its convex surface; its texture was so friable that it broke under the smallest pressure-indeed the organ could not be handled without its giving way; the texture was also dry and granular. It weighed $32 \frac{1}{2} \mathrm{oz}$. There was little or no bile in the gallbladder. The spleen woighed 7 oz., and was pulpy. Except an old adhesion of the upper lobe of the left lung, there was nothing noteworthy elsewhere. On closer examination of the gastro-hepatic adhesion, it was found that the hepatic artery and some branches of the coronary artery lay very much in the focus of the dense neoplastic tissue, and the hepatic artery was distinctly observed to undergo an abrupt diminution in its calibre.

Proceeding now to remark on the pathological events in the foregoing case and to trace their connexion, the cicatrix found in the patient's stomach is obviously the first thing to claim attention. The characters of this cicatrix clearly denote that the pre-existing vlcer was a large one, and that in its extension in depth and progress outwards, having set up adhesive inflammation in the peritoneum, it came to have a thick floor of new tissue, if, indeed, it did not actually invade the contiguous portion of the liver. From the clinical record it is hardly less evident that the ulcer was one of long standing, and in the process of its healing underwent interruptions and relapses. The marked hour-glass deformity of the organ itself attests the magnitude of the lesiun and the abundance of contractile cicatricial tissue. Secondly, we observe that, although there were several small ulcers elsewhere in the stomach, and one pretty large one, there was no appearance of reparative action in any of them ; whence, I think, we may infer that these several ulcers were not in existence when the one above referred to cicatrised, but must have originated at a later period. Thirdly, we find that the hepatic artery and certain branches of the coronary were for a portion of their course involved in the dense neoplastic tissue which united the stomach and liver together in the site of the same cicatrix, which occupied, in fact, the small omentum. In seeking to understand how this came to pass, we must, I think, bear in mind that, besides the cicatricial fibroid tissue repairing the breach in the gastric wall, there were the products of the inflammatory process excited in the adjacent serous membrane, and rekindled with every relapse of ulceration; so that, with exuberant plastic material, the ultimate result, when at length reparation was consummated and the contractile property of the new tissue had come fully into play, would be a lumpy mass in which the normal relation of parts would be very much disturbed and the anatomical detail difficult to make out. The hepatic artery, however, was unmistakably identified, and it was found to be abruptly obstructed. Assuming that the liver is dependent upon this artery for its common nutrition, its condition corresponded; it was much under weight, and its texture was so friable, its cohesion so impaired, that it could not be hendled without giving way. But, in reference to the secondary ulcers observed on the mucous surface of the stomach, and which showed no reparative action, may we not conclude that they owed their origin, in part at least, to a similar constriction of the branches of the coronary artery causing impaired nutrition in the sphere of their distribution? Our next point would seem especially to favour this conclusion. Fourthly, the portion of the stomach included within the pyloric sac (as, for convenience sake, we may call it) was tound to be entirely free from ulceration; it was the healthiest portion of the organ. Now, this, we know, is just the portion that receives its blood supply, not from the coronary artery, but from the gastro-duodenalis, a branch of the hepatic artery, given off before this latter enters the small omentum, and therefore in the present instance before it was subjected to any constricting influence.

(To be concluded).

\section{THE OCCURRENCE OF MENORRHAGIA OR METRORRHAGIA DURING THE FEBRILE STATE.}

\author{
By ALFRED IIANTLE, M.D.
}

IN bringing before the notice of the profession the subject of menorrhagia or metrorrhagia as occurring during a febrile attack, I may at the outset say that my purpose in doing so is for the consideration of the treatment of such cases when the circumstances of some demand treatment. It is necessary to make this proviso, because most certainly the majority of cases of menorrhagia or metrorrhagia occurring during a febrile disease require no treatment; for the loss of blood may be considered to have a salutary effect upon the disease, and nature is probably doing what the practitioner of a generation ago considered the right course of treatment in all febrile diseases.

It is not an infrequent occurrence for zymotic diseases to be ushered in with hæmorrhage. This is frequently observed in the young when scarlatina or measles is making its appearance, at which time the hæmorrhage is most often seen to take place from the nasal mucous membrane. In older patients epistaxis or hæmatemesis is occasionally observed at the outset or early in the course of the fever; whilst in others-and this is particularly the case with measles, scarlatina, small-pox, typhus, typhoid, yellow, and intermittent fevers, and sometimes in pneumonia-the hæmorrhage shows itself from the mucous membrane of the uterus. In some cases this may mean nothing more than the normal process of menstruation taking place, which may or may not have been hastened a few days by the pyrexial attack, and the amount of blood lost may not necessarily be in excess; but in the strong and plethoric, and particularly in small-pox, typhus, typhoid, and yellow fever, the loss may sometimes be excessive and perilous, demanding active treatment. In other instances the hæmorrhage is quite unassociated with the normal menstrual act, when such cases may be said to be ordinary cases of uterine hæmorrhage or metrorrhagia induced by the febrile condition. I believe, however, that by far the largest number of cases of uterine hæmorrhage occurring during a febrile disease take place at or near the proper menstrual period, the circumstances being farourable to an excessive loss of blood. In considering what conditions are favourable to the development of menorrhagia or metrorrhagia during such an attack, we should remember that in the early stages of fever we have a quickened pulse with increased arterial tension. Incidentally, I may remark that in normal menstruation we have increased arterial pressure with slight pyrexia. In the uterus we have an organ with an unusually good blood supply, and, moreover, it is the only organ in the body from which blood escapes normally as a physiological process. With an increased vascular tension, it is only what we might then expect for blood to escape more freely from the mucous membrane, which probably feels and is most influenced by the increase of arterial pressure. A yet stronger factor, however, is probably at work in the causation of hæmorrhage in the febrile state, and it is the alterction in the character of the blood. What these alterations consist of we know as yet little or nothing; but whilst it has been said that in some fevers there is an increase in the fibrinforming constituents of the blood, undoubtedly in others there is a deficiency in these elements, and consequently a marked fluidity and want of coagulability is observed. I believe this to be the case in many of the zymotic fevers.

That the want of the properties of coagulation in uterine hæmorrhage is not explained by its being menstrual blood, and due possibly to the action of the acidity of the vaginal mucus, is proved by the fact that blood coming from the intestinal mucous membrane, or which has been abstracted by the operation of venesection, has the same characters. Trousseau, when speaking of intestinal bæmorrhage during enteric fevers, says," "At the necropsy of persons who have died of enteric fever, we often find bare mesenteric vessels at the bottom of the intestinal ulcerations. Hence it might be supposed that these hæmorrhages are attributable to the rupture of a mesenteric vessel during the process by which 
the furuncular core is eliminated. Still, for the most part, if not always, this is not what occurs. Blood is exuded by the mucous surface exactly as it is in hæmatemesis and epistaxis, as well as in many other similar circumstances. The immediate cause of this sanguineous exhalation is an essential change in the blood, which is in a dissolved statea fact you can verify by examining the blood abstracted from patients in our hospital wards......This particular condition of the blood is seen in a very high degree in the hæmorrhagic putrid fever, and in yellow fever. In scarlatina, diphtheria, measles, and small-pox the blood is also generally in this dissolved state, and to it are attributable the intestinal, renal, and nasal hæmorrhages met with in them. So far is ulceration of the intestine from being a condition essential to the production of hæmorrhages, that they often come on at a period of the disease very far removed from that to which ulceration belongs."

The difficulty and sometimes impossibility of stopping bleeding in fevers was frequently experienced in the days when venesection and the application of leeches were much resorted to in their treatment. Only three years ago 1 was called into consultation with a practitioner of the old school, who, having applied ten leeches to the chest of a child suffering from pneumonia, produced hæmorrhage which was quite uncontrollable, and proved fatal. In these changes of the normal characters of the blood, together with the increased arterial tension, lies the explanation of the profuse menstrual discharge, or the occurrence of hæmorrhage apart from menstruation, during a febrile attack. If the normal menstruation has not taken place recently, and should it not appear during the earlier stages of the fever, in all probability it will not take place during the after progress or convalescence of the disease; and if it should, the arterial pressure being then lessened, the loss of blood may be diminished rather than increased; but occasionally uterine hæmorrhage, either as menorrhagia or metrorrhagia, does appear as a sequel to fevers, when we may consider it as probably due to the changes in the blood alone.

I shall now briefly relate particulars of two cases of menorrhagia which occurred respectively during typhoid fever and small-pox, and which, I may add, are the only two cases I have witnessed requiring treatment.

In October, 1884, I was called to attend a lady, aged forty, the mother of five children, who had been particularly strong and healthy. She had been at a picnic eight days before, when she got her feet very wet. She had since had a good deal of shivering, and for three days previously had suffered with severe neuralgia, for which I was consulted. I found her pulse very quick, and was convinced that the neuralgia was only a symptom. It was evening, and the temperature was $105^{\circ}$. There was a slight pleuritic rub heard on the left side, and pain was complained of; the abdomen was somewhat distended and tender, and there were some ill-defined lenticular spots of a rose colour, but no diarrhoea. Next day the bowels were very loose, the stcols being of a pea-soupy character. The morning temperature was $1046^{\circ}$, and the evening $1048^{\circ}$. I diagnosed the case to be enteric fever. Three days afterwards I was informed that menstruation had taken place. I had been consulted by this lady two months before with reference to the menstrual loss being more than usual; and finding great regularity had persisted for five years, since her last child was born, and no history of miscarriage, whilst other symptoms were complained of, I considered the hæmorrhage due to the meno. pause. The following day (being, as far as 1 could judge, the twelfth day of the disease) the morning and evening temperature were nearly alike; the diarrhoea had ceased, but I learned that the discharge of blood was considerable. There was low muttering delirium almost constantly. Next morning, finding the patient considerably weaker, I became anxious about the loss of blood; and, seeing the enormous quantity of dark liquid blood which, according to my orders, had been saved, having been wrung out of the diapers, determined to administer bæmostatics. Full doses of ergot and gallic acid were given at frequent intervals, also champagne and nourishment. My evening visit found the patient's temperature slightly lower, the pulse greatly softened, but the hæmorrhage quite as free. I was anxious for someone to share the responsibility of the case with me, and at the friends' wish I asked Dr. Gibb to consult with me. Next morning, finding the usual hæmostatic measures of no avail, tincture of digitalis was given every three hours cold applications were applied to the vagina, and 1 remained with my patient most of the day. Eventually I was com- pelled to plug the vagina, after which no hæmorrhage ensued. My patient, however, sunk into a collapsed state; a clammy sweat covered the body, which was cold. I stayed with her the whole night, and, by applying warm bottles and bricks around the body, and administering stimulants and food very freely and frequently, the temperature was recovered. A good reaction taking place, and no recurrence of hæmorrhage, she gradually improved, and, with the best of skilled nursing, made a good recovery. I should scarcely like to estimate the amount of blood lost, but it consisted of several pints of a dark liquid blood, which did not coagulate. The difficulty in this case was, in the first place, to know when to take active measures to stop the bæmorrhage; and, secondly, to find remedies to accomplizh this, for all save that of plugging seemed useless.

The only other severe case I have met with was that of a woman, the wife of a respectable tradesman, who had smallpox. She was at the time suckling an infant. On seeing the nature of the disease, I ordered her to cease doing so. Four days afterwards menstruation, which had been absent during lactation, came on. The patient was a strong woman and in robust health when seized with illness, and the small-pox was confluent in type. 1 was not particularly anxious about the menstrual loss, and, learning that it was not excessive, I did not interfere. I unfortunately could not get a trained nurse, and had to put up with a particularly bad one of the charwoman type, who evidently considered self-protection was the first object to be attained -the means adopted being to saturate herself with whisky. I was misled by this woman as to the quantity of blood actually lost. At my next visit the patient showed signs of anæmia in the mucous membranes, and the pulse was greatly weakened. I discovered the loss was very considerable, and though active remedies were adopted she died. It is probable that if active measures had been taken to stop the bæmorrhage sooner-which, unfortunately, was of a far greater extent than was anticipated - the result might have been different.

As regards the management of such cases of menorrhagia or metrorrhagia, in many instances, as I have already stated, w $\theta$ may consider the loss of blood, if moderate, as beneficial, and we are right in not interfering with it. The uterine mucous membrane may be considered to be acting as a safety valve, and good effects may possibly result by lowering the bloodpressure and the temperature. But we must be very watchful and cautious not to let the hæmorrhage continue too long lest it become almost uncontrollable. I am convinced that we take too little notice of the occurrence of menstruation during a febrile attack. We may or we may not be casually told that our patient is menstruating, and if we are we treat the remark almost with indifference. In other cases we may not hear of it, the nurse or friends of the patient considering it a natural occurrence aud of little consequence. I imagine that in the old days of bloodletting our fathers were accustomed to inquire and take into consideration more than we do the loss of blood by menstruation, for the simple reason that a lowering of the blood-pressure was a part of the treatment in all febrile diseases; and it is, I think, probable that nature's loss frequently saved the operation of venesection. In considering how far the hæmorrhage is beneficial in such cases, we should be greatly guided by the general bodily condition of our patient. We should consider what loss of blood she is capable of sustaining, and be careful to ascertain the former performance of the uterine function, and also learn if our patient is of a hæmorrhagic diathesis. When we have decided that the loss of blood must be checked or stopped, it is not always easily accomplished; the marked fluidity and want of coagulability of the blood in some cases rendering ordinary bæmostatics almost inert, our treatment then must be very active, and, if necessary, plugging of the vagina must be resorted to.

In conclusion, let me suggest that, as careful practitioners, more attention be paid by us to the occurrence of menstrustion during a febrile attack; and let us ascertain whether we have menstruation or uterine hæmorrhage to deal with, bearing in mind that the former is a common term for all forms of uterine hæmorrhage with the laity. It is just possible that by an oversight of this kind we may find, too late perhaps, that a physiological process has stolen a march upon us and insidiously become converted into a pathological and maybe a therapeutical difficulty, and that a hamorrhage which, had it occurred from the nose, lung, stomach, or bowel, would have received every attention at 
our hands, because it has arisen from an organ which periodically bleeds has been deemed unimportant, and not calling for special attention. It may occasionally happen that in such a neglect lies the explanation of the tardy convalescence or fatal termination of some cases which atherwise seem difficult to understand.

Stanley, Durham.

\section{Clinical ates:}

\section{MEDICAL, SURGICAL, OBSTETRICAL, AND THERAPEUTICAL.}

\section{A CASE OF COUPLE RHYTHM OF THE HEART.}

Bx W. J. Collins, M.D., M.S., B.Sc. Lond., F.R C.S. Eng.

"Cotple RHythu" was the name first given by Dr. Hyde Salter in 1871 to a rare and curious abnormality of the rhythm of the heart beat which he had observed in three cases. The subject did not appear to attract the attention of any observer until 1882, when Dr. Henry Cook of Bombay published three cases he had observed in India, and added a sphygmographic tracing. Recent medical treatises and dictionaries of medicine do not contain any account of this curious phenomenon; and as the cases are very rare, it may be interesting to publish the notes of one that I have had under my observation. Before doing so I may say that the peculiarity consists in the cardiac systoles going in pairs or couples, the pause between the two being much less than that which separates one couple from another. It is not a reduplication of both sounds, as is proved by the pulse, the sequence of events being lubb-dup, lubb-dup, pause, lubb-dup, lubb-dup, pause. It is neither an intermittence nor an irregularity, as Dr. Hyde Salter pointed out. It is rather an intermittent irregularity than a regular intermittence, and the irregularity is singularly regular. All three of Dr. Salter's cases had valvular disease of the heart so had two of Dr. Cook's cases, while the other was suffering from malarial fever.

J. R - , aged nineteen, a footman, was first seen by me in January, 1882. He complained of palpitation, which became distressing upon exertion, and was getting worse every year; it had troubled him altogether about five years. He had never had rheumatism, had had measles and whooping-cough, with subsequent bronchitis, at three years old, but since then had enjoyed fair health. The apex beat was in the normal situation, the cardiac dulness not increased; on auscultation, what first of all sounded like reduplication of both sounds was heard, but on listening more cautiously, the couple rhythm described above was very distinctly audible. The pulse, too, exhibited the usual anomaly in these cases. The rate was 48 per minute, and the radial pulse synchronised with the first of each couple. On coughing or exerting himself-e.g, lifting a chair, - the pulse rate was immediately doubled, the second systole of each couple being then also appreciable at the wrist, giving 96 pulsations per minute. A sphygmographic tracing gave an ocular demonstration of the anomaly exhibiting the paired rhythm of the pulse, and the first of each pair being a more powerful systole than the second. There was a short systolic bruit, most distinct at the left base, and presumed to be hæmic in character and causation. It was very remarkable to observe the pulse while the transition from the rapid rate to the exact half of that rate took place; every alternate beat weakened down, until at last it was no longer appreciable to the finger, and sank into the pause. Urine: specific gravity 1026 , acid, no albumen. No other physical signs or symptoms beyond considerable anæmia were observed.

I saw the patient once or twice again in 1882, and each time observed precisely the same phenomena. Then I lost sight of him until April, 1885, when he came complaining of a severe cough which he had had two months, with occasional hæmoptysis; and at the right apex were observed increased vocal vibrations and crackling crepitation, while at the left apex were coarse breath sounds. The couple rhythm was still present, but less marked than formerlythat is to say, the pause between the members of a couple approximated to that between two couples. As an opportunity to go to Australia presented itself, he left England in
August, 1885. I heard from him in December last from Lithgow (New South Wales). Alas! the voyage had apparently aggravated his lung trouble, and he entered Sydney Hospital on landing with both lungs seriously diseased. Quite recently I have been informed of his death.

In the absence of any better explanation of this rare and striking phenomenon I would suggest as its cause a rhythmic rise and fall in the activity of the medullary cardio-inhibitory centre, akin to the rhythm which we know to exist in the respiratory and vaso-motor centre; this would produce an alternate reining up and relaxation of the heart's spontaneity, and so occasion the symptom described.

\section{ON THE TREATMENT OF HYDATIDS.}

By Arthur Senvett, M.D. Aberd., \&c. FORMERLY HOUSE-SURGEON, LONDON HOSPITAL.

In The Lancet of Jan. 15th, 1887, Mr. Laurence Humphry describes a case of hydatid cyst of the liver, in which collapse and an urticarial eruption followed as the result of puncture with a hypodermic needle, and which was afterwards cured by evacuating the cyst. I believe this method is generally adopted, the aspirator or trocar and cannula being used, and the cyst completely emptied. In this country, where the disease prevails, such is the general practice; and 1 have operated on about a hundred cases in this manner. with a fair percentage of recoveries. My notes do not extend over all the cases, but about ten deaths out of the hundred would be nearly, if not exactly, correct. The conclusion, however, has been forced upon me that this treatment is not the best, and during the last year I have treated each case by puncturing, using a large hypodermic syringe with two needles, drawing off about two drachms of the fluid, and then injecting a similar quantity of a weak solution (two grains to the pint) of perchloride of mercury. The result of each case has been satisfactory; no suppuration has resulted, and the cyst has gradually contracted. The generally accepted principle that collections of fluid in the internal parts of the body should not be suddenly evacuated is thus not violated. The action of the perchloride, even in such minute quantities, is sufficient to destroy the vitality of the echinococcus, which is never great, and the spontaneous method of cure is simulated as nearly as possible. That many cases do get well spontaneously is shown by the fact that in fully one-third of the necropsies I have made at the Hamilton Hospital on men who have lived in the bush for a length of time, and who have been accustomed to drink any water that they might meet with, a shrunken cyst has been found. I am not aware if the above method of treating this disease has been previously described, nor have I opportunities of referring to the literature of the subject. It seems to me to meet the indications and to be based on scientific principles.

Hamilton, Victoria.

\section{FRACTURE OF ASTRAGALUS; SUBSEQUENT NECROSIS;} REYOVAL OF CARIOUS BONE; RECOVERY.

\section{By ARTHUR E. SALter, M.B.}

ON August 3rd, 1886, I attended a child (S. C- - ), aged four years and four months, with an injury to her left ankle joint, caused by her falling from the top of a heap of house studs, some of the timber falling on the ankle. When I saw her she was in great pain, the accident only having just happened. There was no bruising, but the foot was displaced a little outwards, and there was a large effusion of blood heneath the skin on the inside. She was in intense pain. Having chloroformed her and examined the joint, there was crepitation distinctly below the joint, the inner malleolus was broken. Believing the fragments would unite well, I put up the limb in a splint, guarding against pressure over the effused blood, and in this way it was left for a few days, at the end of which, as great pain was complained of, the splint was removed. The limb having been again put up, it was left for three weeks, when a plaster splint was applied and kept on for another three weeks, after which, the pain commencing to be great, the splint was removed, whereupon some signs of approaching suppuration were visible. In this position it was left without any splint, and on 